\title{
VI. On the sudden acquisition of conducting-power by a series of discrete metallic particles
}

\section{Prof. Oliver J. Lodge}

To cite this article: Prof. Oliver J. Lodge (1894) VI. On the sudden acquisition of conductingpower by a series of discrete metallic particles, Philosophical Magazine Series 5, 37:224, 94-95, DOI: $10.1080 / 14786449408620524$

To link to this article: http://dx.doi.org/10.1080/14786449408620524

曲 Published online: 08 May 2009.

Submit your article to this journal $[\pi$

Џ Article views: 4

Q View related articles $\square$

Citing articles: 1 View citing articles 5 


\section{Conducting-Power of Discrete Metallic Particles.}

a minute or so. Doubtless this is due to the fact that, as the film gets more hard and less plastic, the metallic particles find it more difficult to move, by rotation or otherwise, in their environment.

Finally, these films are very much less sensitive to mechanical disturbances given to their supports than the tubes of filings. They do not appear to be susceptible to the action of heat; but in many instances their conductivity was destroyed by breathing upon them, or by allowing a stream of steam to strike their surfaces, the conductivity being always restored by the electromagnetic radiations. The more rapid vibrations of light have not produced any effect so far as my observations have gone.

The prime cause of the action is to be sought in the electrical surgings produced in the leads $s$ and $w$; but it is clear that the state of affairs at the places $P, Q$ of contact of the film with the electrodes is a most important matter.

It seems clear, therefore, that the sensitized surface in an impulsion-cell has a close analogue in a slightly plastic film filled with almost mathematical completeness by fine metallic particles.

VI. On the Sudden Acquisition of Conducting-Power by a Series of Discrete Metallic Particles. By Prof. OLIVER J. LODGE*.

TWHE recent experiments of Mr. Croft and Prof. Minchin 1 remind me of an observation I frequently made when engaged with the syntonic arrangement of Leyden-jar circuits, or sympathetic electric resonance. I found, if the knobs of the receiver were very close together, a weak battery and bell being in circuit, that the occurrence of a scintilla at the receiver frequently caused the bell to ring for some time, and in general to show signs that the knobs were in a state of feebly adhesive contact. It was just as if their surface-layers or skins had been broken throngh, or opened out, in such a manner as to increase the molecular range of a few of the closest superficial molecules and thereby to cause cohesion to set in at a distance considerably greater than the ordinary distance.

A phenomenon which may be similarly caused is that discovered by Lord Rayleigh, with regard to the effect of electrified sealing-wax near a vertical water-jet : drops which would otherwise have rebounded being thereby caused to cohere. And, by the method of two impinging jets, the necessary

* Communicated by the Physical Society: read November 24, 1893, as a contribution to the discussion on Prof. Minchin's paper. 
difference of potential was shown to be only a volt or two, since a pair of impinging jets ceased to rebound if connected to the opposite terminals of a Grove cell.

Once more, the effect first observed by Mr. Guitard (1850), and rediscovered by myself and the late J. W. Clark, concerning the adhesion of dust-particles or mist-globules in electrified air, is but a more violent variety of the same sort of effect. And the action of electricity on a steam-jet discovered by Robert von Helmholtz and afterwards by Shelford Bidwell, and worked at by Richarz, Aitken, J. J. Thomson, and others, may not be very different.

Thinking of the Lord Rayleigh variety of experiment as in many respects the most definite, it is natural to explain it electrolytically as due to the polarisation of the water-drops, or the formation in each drop of molecular chains each with a negatively charged oxygen atom at its termination on one hemisphere and a positively charged hydrogen atom at its opposite extremity.

Such drops then colliding about the region of their poles would be attracted not only by their ordinary cohesive forces, but by electrical force also, and thus the effective molecular range would be increased and cohesion might set in over an unusual distance.

In some such way I have allowed myself to fancy that the adhesion of my knobs might be explained, and I suggest that the conductivity of a chain of metallic filings under an electric polarising influence may be due to something of the same cause.

That a tap should break the minute points of contact is likely enough, though I see no reason why another tap should restore communication,-if so it does.

At the last moment I write this and send it off in the hope that it may arrive in time to be read at the Meeting as a contribution to the discussion on these interesting experiments.

Nov. 23, 1893.

VII. On the Magnetic Shielding of Concentric Spherical Shells. By A. W. RÜCKER, $F . R . S . *$

QPECIAL interest has of late attached to the problem of $N$ shielding magnetic forces by means of iron screens, and recently the Astronomer Royal has described the arrangement (designed by Messrs. Johnson and Phillips) by which

* Communicated by the Physical Society : read November 24, 1893. 